\title{
Performance Dynamics of International Exchange-Traded Funds
}

\author{
Stephen Bahadar *, Christopher Gan $『$ and Cuong Nguyen \\ Department of Financial and Business Systems, Lincoln University, 21 Ellesmere Junction Road, Lincoln, \\ Christchurch 7674, New Zealand; Christopher.Gan@lincoln.ac.nz (C.G.); Cuong.Nguyen@lincoln.ac.nz (C.N.) \\ * Correspondence: Stephen.Bahadar@lincoln.ac.nz
}

Received: 27 June 2020; Accepted: 29 July 2020; Published: 1 August 2020

\begin{abstract}
Asynchronous trading hours between the markets of Exchange-Traded Funds (ETFs) and their benchmarks not only make it difficult to apply a full replication strategy but also make the creation/redemption process ineffective and consequently distress the performance of international ETFs. Despite the exponential growth of the ETF industry in general and international ETFs in particular, the performance of international ETFs is under-researched. Therefore, this study evaluates the performance of US-listed international ETFs by analyzing the returns, volatilities, tracking ability and pricing efficiency. The study findings are useful for investors interested in understanding the performance dynamics of international ETFs.
\end{abstract}

Keywords: ETFs; return and volatility; tracking error; premium and discount

\section{Introduction}

Despite persistent economic and political volatility, the Exchange-Traded Fund (ETF) industry continues to experience popularity and growth since the invention of the first ETF. In the process, it broke new records in terms of numbers of ETFs and assets under management (AuM), Strong growth in exchange-traded fund (ETF) assets is expected to continue with assets under management (AuM) on track to reach US $\$ 7$ trillion by 2021 (PwC 2016). However, by the end of 1997, there were only two ETFs with an AuM value of US\$ 6.2 billion (Ferri 2011).

This growth of the ETF industry is not just in scale but in sophistication as well. There is now a variety of ETFs catering different investment needs of the global investors, and international ETFs are one of these sophisticated types of ETFs. International ETFs were first introduced in 1996 by Black Rock Inc., the world's largest ETF provider (Chen and Nicholas 2020). The objective of international ETFs is to facilitate every investor, including institutional and retail investors, to directly invest and obtain exposure to promising global capital market indices from their home country stock exchanges (Levy and Lieberman 2013). Previously it was difficult for investors to directly invest in certain foreign markets due to a number of restrictions on international capital flow such as capital market, exchange rules and regulations, extreme transaction costs and higher costs of information (Chang et al. 1995). For example, international investors need QFII (qualified foreign institutional investor) license to trade in the Chinese "A-share" market, which comprises of the $75 \%$ of the total market capitalization of over 2000 Chinese firms (Mistry 2013). These barriers have stimulated the innovation of many investment products to facilitate international investment. These products include International Mutual Funds, American Depository Receipts (ADRs), Closed-End Country Funds (CECFs) and International ETFs, which are the most popular of all. This is because of their unique hybrid structure, which simultaneously possesses the characteristics of stocks and mutual funds.

In addition, international ETFs bear some very distinguishing features such as continuous trading, higher international diversification, lower management fee and higher tax efficiency (Rompotis 2015) 
but at the same time, they may suffer from the issues of great importance such as pricing inefficiency and tracking error. According to Engle and Sarkar (2006), international ETFs trade at a larger premium or discount and more persistent compared to the domestic ETFs. This is because of the difference in trading hours between the markets of international ETFs and benchmark indices. Hughen and Mathew (2009) argue that asynchronous trading hours causes information asymmetry in ETFs' market, which does not let international ETFs fully replicate the performance of their underlying indices.

The motivation of this study is twofold. The first is to employ the type of 'replication strategies' used by international ETFs to mirror the performance of their underlying indices. Generally, passively-managed ETFs use physical (either full or optimized) strategies and actively-managed ETFs employ synthetic replication strategies to mirror the performance of their benchmarks. The physical replication strategies are relatively expensive in terms of transaction costs (which refers to the buying and selling of underlying securities. It is not included in the expense ratio (or management fee) charged by the ETF issuers), especially for broad indices that are composed of hundreds of securities or indices which consist of volatile and illiquid securities (Maurer and Williams 2015). According to Dickson et al. (2013), the ETFs (whether domestic or international), following any physical replication strategy, are less likely to consistently track their benchmark indices and expose investors to the risk of tracking error. Svetina (2010) compares the tracking performance of domestic ETFs to international ETFs and confirms that the tracking error of international ETFs is more than double that of domestic ETFs.

The second is to assess the unique Creation/Redemption process of ETFs, which takes place in the primary market between the authorized market makers and the ETF issuer. Thus, the Creation/Redemption of ETF shares immediately arbitrages away the price discrepancies of ETFs in the secondary market (i.e., the stock exchange). Ma (2015) argues that the Creation/Redemption process is effective only if the ETF shares and underlying securities are traded synchronically, as in the case of domestic ETFs; however, for International ETFs there are asynchronous trading hours between the markets of international ETFs and benchmark indices. For instance, Asian-Pacific markets have completely asynchronous trading hours with the US market, while the European markets only have partially synchronous trading hours with the US market (Levy and Lieberman 2013). In such cases, the arbitrage mechanism becomes ineffective (Campbell et al. 1997). Consequently, the trading prices of international ETFs fluctuate during the US trading day while their net asset values (NAVs) remain stale and thus make international ETFs to trade at large premiums or discounts compared to their underlying foreign stale NAVs (Shum 2010).

This study empirically examines the performance of US-listed international ETFs offering exposure to the Asia-Pacific and the European markets. Our particular interest is to evaluate the trading performance of the US-listed international ETFs in terms of return and volatility, tracking efficiency and pricing efficiency. This study has several distinct contributions to the extant literature on international ETFs. First, the study examines the distinguishing behavior of returns and volatility estimated in trading prices and NAVs of international ETFs. Second, it provides intraday and overnight return and volatility analyses of international ETFs. Third, the study investigates how well the international ETFs track the performance of their benchmark indices using three different measures of tracking error; also, in case there is any tracking error, the study also determines the persistence of tracking error using the second-order autoregressive AR (2) model. Finally, we evaluate the pricing efficiency of international ETFs in terms of premiums or discounts and test whether premiums or discounts persist over time using the second-order autoregressive AR (2) model.

The remaining of the paper is organized as follows. Section 2 discusses the previous empirical literature on the performance of international ETFs. Section 3 presents the methodology, Section 4 is about the sample of the study while Section 5 discusses results and conclude the study. 


\section{Literature Review}

Ever since the introduction of the first international ETF in 1996, several studies have endeavored to analyze the performance and efficiency of international ETFs by considering their daily, intraday and overnight returns and volatilities, tracking efficiency (Purohit et al. 2014; Ramos 2015) and pricing efficiency (Delcoure and Zhong 2007; Engle and Sarkar 2006).

The returns and volatilities of international ETFs are calculated in terms of their trading prices or their NAV. Previous studies (e.g., (Rompotis 2015; Tse and Martinez 2007)) compare returns and return volatilities estimated using trading prices and NAV. Rompotis (2015) reports that the mean NAV return is higher than the closing price return, whereas the closing price return variance is found to be higher than the NAV return variance. Moreover, Tse and Martinez (2007) perform return variance analyses and report that the closing price return variance is higher than the NAV return variance. Tse and Matinez further argue that the higher differences between price return variance and the NAV return variance indicate the existence of more noise trading of international ETFs.

For a more precise understanding of the return and volatility behavior of international ETFs, many previous studies (Gutierrez et al. 2009; Kang and Babbs 2012; Tse and Martinez 2007) separately measure and compare the intraday and overnight returns and the volatilities of international ETFs. Some studies find that the overnight mean returns are greater than the intraday mean returns; other studies find contrary results that mean returns during the trading hours are greater compared to during non-trading hours. According to Tse and Martinez (2007), the intraday and overnight mean return variances of international ETFs are $62 \%$ and $77 \%$, respectively. In another study by Gutierrez et al. (2009) the overnight return volatility is also found to be higher than the intraday return volatility for the case of ETFs tracking Asian indices; the authors attributed their findings to the release of public information during the trading session of the underlying markets. In addition, Kang and Babbs (2012) examine fifteen equity ETFs and find that overnight returns on the funds have higher means, lower variances and distributions with fatter tails than intraday returns.

Engle and Sarkar (2006) emphasize the importance of another important performance metric (i.e., pricing efficiency) of the international ETFs. They argue that the pricing inefficiencies in international ETFs are relatively more persistent and difficult to eliminate through the creation/redemption process. Several previous studies (Ackert and Tian 2008; Delcoure and Zhong 2007; Levy and Lieberman 2013) endorse that the deviations of the trading price of international ETFs from their NAVs are more material, frequent and persistent compared to other ETF types. Engle and Sarkar (2006) compare the pricing efficiency of 21 domestic and 16 international ETFs on a daily and intra-day basis. They find that domestic ETFs have very small premiums that last for few minutes while international ETFs have larger and more persistent premiums that last for three hours or take longer to adjust. The findings of Ackert and Tian (2008) are also consistent with the findings of Engle and Sarkar (2006). Ackert and Tian (2008) examine the pricing efficiency of 7 domestic and 21 international ETFs and conclude that international ETFs trade at a larger premium compared to the domestic ETFs. However, Delcoure and Zhong (2007) exclusively sample 20 international ETFs and find that these ETFs trade at significant premiums which usually persist for one or two days. Moreover, Levy and Lieberman (2013) study 17 US-listed international ETFs and find that the prices of these ETFs are mainly driven by their NAVs during the synchronized trading hours while during the asynchronous trading hours, the S\&P 500 Index has the dominant effect on the pricing of international ETFs.

Tracking ability is another important performance metric of the international ETFs. The tracking ability is the ability of international ETFs to replicate the performance of their foreign tracking indices. A number of studies (Blitz and Huij 2012; Shin and Soydemir 2010; Svetina 2010) report the tracking error of international ETFs. Blitz and Huij (2012) compare the tracking efficiency of international ETFs tracking of developed and developing market indices and report that the tracking errors of international ETFs with developing markets' benchmark indices are greater than the tracking errors indices of developed markets. However, Svetina (2010) notes a higher tracking error for international ETFs compared to for domestic ETFs, suggesting transaction costs as the possible reason for this. 
Moreover, Shin and Soydemir (2010) find that ETFs tracking foreign indices are exposed directly to the exchange rate risk, unlike those that track the U.S. indices. This is why the tracking error of international ETFs is relatively higher than that of domestic ETFs.

\section{Data and Research Design}

The sample of this study comprises of 56 US-listed international ETFs offering Asia-Pacific and European market exposure to investors. All constituents of the sample have following characteristics in common: (1) they are created by Black Rock with the iShares brand; (2) they all are listed on US exchanges; (3) they either track single-country or broad-market indices of Asia-Pacific and Europe; (4) they all are passively-managed ETFs; and (5) the underlying indices of all sample ETFs are equity focused; as different asset classes have different dynamics, we limited the scope of this study to only select international ETFs which track the performance of equity-based tracking indices. Daily historical data of sample ETFs were downloaded from the Bloomberg database for a 10 years' time span from 1 January 2010 to 31 December 2019. The profiles of sample international ETFs are given in Appendix A.

The scope of this study is to evaluate the performance of international ETFs by analyzing the (1) daily, intraday (trading hours) and overnight (non-trading hours) performance, (2) the tracking performance and persistence of tracking error and (3) the pricing inefficiency and persistence of premiums or discounts. More detail is given in Table 1.

Table 1. Research design.

\begin{tabular}{cl}
\hline \multicolumn{1}{c}{ Performance Metrics } & \multicolumn{1}{c}{ Method } \\
\hline (1) Return and risk analyses of international ETFs & $\begin{array}{l}\text { Analyze daily return and volatility of international ETFs } \\
\text { Analyze intraday and overnight return and volatility of } \\
\text { international ETFs }\end{array}$ \\
\hline \multirow{3}{*}{ (2) Tracking performance of international ETFs } & $\begin{array}{l}\text { Measure tracking error in international ETFs } \\
\text { Examine the persistence of tracking error in international } \\
\text { ETFs over time. }\end{array}$ \\
\hline \multirow{3}{*}{ (3) Pricing inefficiency of international ETFs } & $\begin{array}{l}\text { Measure pricing inefficiency of international ETFs } \\
\text { Examine the persistence of pricing inefficiency of } \\
\text { international ETFs over time. }\end{array}$ \\
\hline
\end{tabular}

Note: This table explains the complete research design of the study.

\section{Empirical Results}

\subsection{Return and Volatility Analyses of International ETFs}

4.1.1. Does the Measurement of Daily Return and Volatility of International ETFs in Terms of Trading Price and NAV Matter?

ETF investors receive the NAV returns (Rompotis 2015) and the associated cash flows e.g., dividend payments of the underlying can flow to the ETF shares, as a percentage of NAV on their investments while most of the retail investors calculate returns in trading price which are more frequently and easily available compared to the NAVs. We, therefore, compute the returns of international ETFs both in trading prices and in NAVs to determine if there is any significant difference in the two returns series. Likewise, the study also examined the differences in volatilities of the trading price return and the NAV return.

Our findings in Table 2 suggest that the mean NAV return (volatility) is higher (lower) than the mean trading price return (volatility) of both Asia-Pacific and European ETFs. These results are consistent with the findings of Pontiff (1997) on close-end funds and Rompotis (2015) on country ETFs; both reports suggest that the trading prices are more volatile than their NAVs. On the basis of benchmarks, the returns ratio $\left(R_{E T F} / R_{N A V}=0.8367\right)$ and the volatilities ratio $\left(\sigma_{E T F} / \sigma_{N A V}=1.0732\right)$ 
for European ETFs are closer to one, reflecting that European ETFs are better than the Asia-Pacific ETFs, which is consistent with the findings of Shin and Soydemir (2010).

Table 2. Daily return and volatility analyses of International Exchange-Traded Funds (ETFs).

\begin{tabular}{ccccccc}
\hline & \multicolumn{3}{c}{ Asia-Pacific ETFs } & \multicolumn{3}{c}{ European ETFs } \\
\hline & Price-Based & NAV-Based & Ratio & Price-Based & NAV-Based & Ratio \\
\hline Return & (a) & $\mathbf{( b )}$ & $\mathbf{( a / b )}$ & (c) & (d) & (c/d) \\
Volatility & 0.0054 & 0.0080 & 0.6750 & 0.0041 & 0.0049 & 0.8367 \\
\hline
\end{tabular}

Note: This table reports daily mean values of the trading price return $\left(R_{E T F}\right)$, the NAV return $\left(R_{N A V}\right)$, trading price return volatility $\left(\sigma_{E T F}\right)$, the NAV return volatility $\left(\sigma_{N A V}\right)$; the table also reports two corresponding ratios: first between the trading price and the NAV returns $\left(R_{E T F} / R_{N A V}\right)$ and second between the trading prices and the NAV return volatilities $\left(\sigma_{E T F} / \sigma_{N A V}\right)$ for the sample Asia-Pacific and European ETFs. If the ratio $\left(R_{E T F} / R_{N A V}\right)$ is greater than one, it implies that the trading price return is higher than the NAV return and vice versa. On the other hand, if the ratio $\left(\sigma_{E T F} / \sigma_{N A V}\right)$ is greater than unity, it means that the volatility in trading price return is higher than the NAV return volatility.

\subsubsection{What Is the Difference between Intraday and Overnight Performance of International ETFs?}

In order to determine the difference between the volatilities during the trading and non-trading hours and to identify the cause of that difference, we compared the standard deviations of intraday and overnight returns of international ETFs. In previous literature (Chan et al. 2000; Rompotis 2015; Tse and Martinez 2007), the volatility in the assets traded on the stock markets was ascribed to one of three factors: the release of accumulated public information, more noise trading during the trading hours or the release of more private information. To be more specific, the return volatility is either linked to the trading activity (e.g., the noise trading or the release of private information) or the information flow (e.g., the release of accumulated public information). The possible reason for the earlier relationship is the synchronous trading hours, while the reason for the latter is due to the asynchronous trading hours between ETFs and their benchmark.

Therefore, if volatility is caused by the release of accumulated public information, then overnight return volatility is greater than the intraday return volatility of ETFs, which are asynchronous in trading hours compared to their benchmarks indices; otherwise, for the case of synchronous trading hours between ETFs and their benchmarks, intraday return volatility is greater than overnight return volatility. If noise trading or release of private information causes the volatility, then intraday return volatility is seen to be greater than the overnight return volatility of ETFs.

Our findings show that intraday return (volatility) is lower (higher) than the overnight return (volatility), irrespective of the benchmark market (see Table 3). Based on our findings, we can conclude that the release of accumulated public information during the trading hours is the reason for higher overnight return volatility compared to the intraday return volatility of international ETFs with asynchronous trading hours as their underlying indices. On the bases of benchmarks, the returns ratio $\left(R_{\text {day }} / R_{\text {night }}=0.8108\right)$ and the volatilities ratio $\left(\sigma_{\text {day }} / \sigma_{\text {night }}=0.8635\right)$ for European ETFs are closer to one, reflecting that European ETFs are better than the Asia-Pacific ETFs. Our findings, that the overnight return volatility among European ETFs is relatively lower than the overnight return volatility of Asia-Pacific ETFs, support the argument that European markets are relatively more matured and developed, even though they only have partial synchronous trading hours with the US market while the Asia-Pacific market has full synchronous trading hours with the US market (Levy and Lieberman 2013). 
Table 3. Intraday and overnight return and risk analyses.

\begin{tabular}{ccccccc}
\hline & \multicolumn{3}{c}{ Asia-Pacific ETFs } & \multicolumn{3}{c}{ European ETFs } \\
\hline & Intraday & Overnight & Ratio & Intraday & Overnight & Ratio \\
\hline Return & $\mathbf{( a )}$ & $\mathbf{( b )}$ & $\mathbf{( a / b )}$ & (c) & (d) & (c/d) \\
Volatility & 0.0080 & 0.0149 & 0.5369 & 0.0090 & 0.0111 & 0.8108 \\
& 1.0270 & 1.3137 & 0.7817 & 1.0368 & 1.2006 & 0.8635 \\
\hline
\end{tabular}

Note: This table reports the mean values of the intraday return $\left(R_{\text {day }}\right)$, overnight return $\left(R_{\text {night }}\right)$, intraday return volatility $\left(\sigma_{\text {day }}\right)$, overnight return volatility $\left(\sigma_{\text {night }}\right)$; the table also reports a pair of corresponding ratios: first between the intraday and overnight returns $\left(R_{\text {day }} / R_{\text {night }}\right)$ and second between the intraday and overnight return volatilities $\left(\sigma_{\text {day }} / \sigma_{\text {night }}\right)$. If the ratio $\left(R_{\text {day }} / R_{\text {night }}\right)$ is greater than one, it implies that intraday return is higher than the overnight return and vice versa. However, if the ratio $\left(\sigma_{\text {day }} / \sigma_{\text {night }}\right)$ is greater than unity, it means that intraday return volatility is higher than overnight return volatility.

\subsection{Tracking Ability of International ETFs}

\subsubsection{Do International ETFs Exactly Mimic the Underlying Benchmarks?}

The term 'tracking error' refers to the deviation in returns of passively managed investment products and their benchmarks, whose performance they try to imitate (Pope and Yadav 1994). The literature (Frino and Gallagher 2001; Pope and Yadav 1994; Roll 1992) on the index funds suggests several methods to measure tracking error such as the average raw return difference between the passive funds and the indexes. Following Frino and Gallagher (2001), we used two methods to estimate tracking error. The first method estimates tracking error as the average term of the absolute differences in ETF and their benchmark returns. The second method computes tracking error as the standard deviation of the daily differences in ETF and their benchmark returns. Finally, we calculated the average of the tracking errors estimated using the two aforementioned methods.

Once the estimation tracking errors were obtained using the trading price returns, we repeated the method to estimate NAV returns. The purpose of calculating the tracking errors in trading price and NAV returns is to compare and determine which one of the two is superior in tracking their underlying indices.

Our results, as reported in Table 4, show that the average tracking errors based on NAV returns are lower than the average tracking errors based on trading prices return, regardless of the benchmark market. This implies that NAV is more efficient in tracking the performance of underlying indices than the trading prices. The tracking errors in terms of trading price returns are inflated, indicating that the trading price provides an unreliable ETF performance measure relative to the NAV. We also note that European ETFs are superior in tracking efficiency compared to the Asia-Pacific ETFs. For the European ETFs, the mean TE in terms of trading price returns and NAV returns are $0.7359 \%$ and $0.0850 \%$, which are significantly lower compared to the mean values of the Asia-Pacific ETFs which are $1.0246 \%$ and $0.1178 \%$, respectively. Our findings, on the superior tracking abilities of the European ETFs over the Asia-Pacific ETFs, are consistent with the results of Shin and Soydemir (2010). 
Table 4. Tracking errors of International ETFs.

\begin{tabular}{|c|c|c|c|c|}
\hline & \multicolumn{2}{|c|}{ Asia-Pacific ETFs } & \multicolumn{2}{|c|}{ European ETFs } \\
\hline & $\begin{array}{c}\text { Tracking } \\
\text { Error between } \\
R_{E T F} \text { and } R_{I n d}\end{array}$ & $\begin{array}{l}\text { Tracking Error } \\
\text { between } \\
R_{N A V} \text { and } R_{I n d}\end{array}$ & $\begin{array}{c}\text { Tracking Error } \\
\text { between } \\
R_{E T F} \text { and } R_{I n d}\end{array}$ & $\begin{array}{c}\text { Tracking Error } \\
\text { between } \\
R_{N A V} \text { and } R_{\text {Ind }}\end{array}$ \\
\hline$T E_{1}$ & 0.9270 & 0.1034 & 0.6593 & 0.0764 \\
\hline$T E_{2}$ & 1.1222 & 0.1323 & 0.8125 & 0.0937 \\
\hline Mean TE & 1.0246 & 0.1178 & 0.7359 & 0.0850 \\
\hline
\end{tabular}

Note: This table presents the tracking errors of Asia-Pacific and European ETFs estimated in both trading price return and NAV return. We used two methods to estimate tracking error: (1) the absolute difference in trading price (or NAV) returns and its benchmark returns, and (2) the standard deviation of the difference in trading price (or NAV) returns and its benchmark returns. The mean TE of the two both methods are also reported in this table.

\subsubsection{Does the Tracking Error in International ETFs Persist over Time?}

Having computed the tracking error, we next investigated the persistence of tracking error in international ETFs. To examine the persistence, we estimated the second-order autoregressive model AR (2) by regressing the tracking error on the values of two lagged day as follows:

$$
\begin{gathered}
T E 1_{E T F, t}=\alpha+\beta_{1} T E 1_{E T F, t-1}+\beta_{2} T E 1_{E T F, t-2}+\varepsilon_{t} \\
T E 1_{N A V, t}=\alpha+\beta_{1} T E 1_{N A V, t-1}+\beta_{2} T E 1_{N A V, t-2}+\varepsilon_{t}
\end{gathered}
$$

where $T E 1_{E T F, t}$ is the average absolute difference between trading price return of ETFs and their corresponding benchmark returns and $T E 1_{N A V, t}$ is the average absolute difference between NAV return of ETFs and their corresponding benchmark returns. The positive and significant $\beta_{1}$ and $\beta_{2}$ coefficients imply that the tracking error persists for one and two days, respectively; the negatively significant estimates mean that the tracking error exhibits mean-reverting behavior. Finally, non-significant $\beta_{1}$ and $\beta_{2}$ coefficients show the lack of persistence and significant alpha $(\alpha)$ indicates that a constant portion of replication inefficiency remains unexplained by the lagged values of tracking error.

The results of autoregressive modes reveal that alpha $(\alpha)$ coefficients are statistically significant irrespective of the underlying markets (i.e., Asia-Pacific and European markets) and the types of tracking errors (i.e., $T E 1_{E T F, 1}$ and $T E 1_{N A V, 1}$ ). These results imply that a significant portion of tracking errors remain unexplained by their lagged values. For both Asia-Pacific and European ETFs, the alpha $(\alpha)$ coefficients are higher for tracking errors based on trading price returns compared to the NAV return based tracking errors, which shows that tracking errors based on NAV returns is relatively more efficient and can be mainly explained by their lagged values.

In terms of the impact of past values, the $\beta_{1}$ and $\beta_{2}$ coefficients are positive and significant for both Asia-Pacific and European ETFs, implying that the tracking errors persist in almost all international ETFs for two days but it diminishes over time, as $\beta_{2}<\beta_{1}$. We also note that tracking errors are less persistent in European ETFs and quickly fade away compared to for the Asia-Pacific ETFs, since the magnitude of $\beta_{1}$ and $\beta_{2}$ coefficients for European ETFs (see Column 3 and 4 in Table 5) are less than that of Asia-Pacific ETFs (see Column 1 and 2 in Table 5). In addition, we also found that the tracking efficiency in terms of NAV returns is higher relative to the trading price return, meaning that tracking errors more quickly diminish if they are measured using the NAV. The magnitude of $\beta_{1}$ and $\beta_{2}$ coefficients for NAV based tracking errors (see Column 2 and 4 in Table 5) are less than that of trading price return based tracking errors (see Column 1 and 3 in Table 5) in both Asia-Pacific and European ETFs. These results are consistent with our baseline results indicating that NAV is the better performance indicator and that European ETFs are more efficient. For the robustness of our results, we re-ran our analyses with a maximum of four lagged values of tracking error but our results (unreported) remain unchanged, which confirms the significant persistence of the tracking error for two days. 
Table 5. Persistence of tracking errors in international ETFs.

\begin{tabular}{lcccc}
\hline & \multicolumn{2}{c}{ Asia-Pacific ETFs } & \multicolumn{2}{c}{ European ETFs } \\
\hline & $T E 1_{E T F, t}$ & $T E 1_{N A V, t}$ & $T E 1_{E T F, t}$ & $T E 1_{N A V, t}$ \\
\hline \multirow{2}{*}{$\alpha$} & $\mathbf{( 1 )}$ & $\mathbf{( 2 )}$ & $\mathbf{( 3 )}$ & $\mathbf{( 4 )}$ \\
\hline \multirow{2}{*}{$\beta_{1}$} & $0.5861^{* * *}$ & $0.0343^{* * *}$ & $0.2751^{* * *}$ & $0.0656^{* * *}$ \\
& $(0.1243)$ & $(0.0189)$ & $(0.0987)$ & $(0.0325)$ \\
\hline \multirow{2}{*}{$\beta_{2}$} & $0.5657^{* * *}$ & $0.4999^{* * *}$ & $0.4306^{* * *}$ & $0.2217^{* * *}$ \\
& $(0.2570)$ & $(0.2578)$ & $(0.2450)$ & $(0.0781)$ \\
\hline Number of ETFs & $0.2534^{* * *}$ & $0.1494^{* * *}$ & $0.137^{* * *}$ & $0.0855^{* * *}$ \\
Number of Observations & $(0.0370)$ & $(0.0250)$ & $(0.0283)$ & $(0.0480)$ \\
$F-$ Stat $(p-$ value) & 28 & 28 & 28 & 28 \\
$R^{2}$ & 0.000 & 2120 & 2250 & 2250 \\
\hline
\end{tabular}

Note: This table reports the results of model (1): TE1 $T E 1_{N A V, t}=\alpha+\beta_{1} T E 1_{N A V, t-1}+\beta_{2} T E 1_{N A V, t-2}+\varepsilon_{t}$. Prior to applying autoregressive models, we examined the random walk characteristics of the tracking errors measured in trading price and NAV using Lo and MacKinlay's (1988) individual variance ratio and Chow and Denning's (1993) multiple variance ratio with homoscedastic and heteroscedastic test estimates. Also in unreported results, we found that the tracking errors of both Asia-Pacific and European ETFs do not follow the random walk and can be predictable based on the historical values. The standard errors for the estimated coefficients are heteroscedasticity and autocorrelation consistent standard errors (Newey and West 1987). “****" represents the significance at the $1 \%$ level.

\subsection{Pricing Inefficiency of International ETFS}

\subsubsection{Do International ETFs Suffer from Pricing Inefficiency?}

The trading prices of international ETFs generally deviate from their NAVs (Delcoure and Zhong 2007) and ETFs either trade at a premium or a discount to their NAVs. To measure the pricing efficiency in terms of the premium and discount, we used two methods. First, we calculated the difference between the closing price of ETF on day $t$ and the closing NAV of ETF on day $t$ and scaled this by the closing NAV of ETF on day $t$.

We then regressed the trading price of ETF on its NAV using the ordinary least square (OLS) method, which is a method for measuring the pricing discrepancies in international ETFs.

$$
C P_{E T F, t}=\alpha+\beta_{1} C P_{N A V, t}+\varepsilon_{t}
$$

International ETFs are efficiently priced if the $\beta_{1}$ coefficient is statistically significant and equals to one; however, if the coefficient is statistically significant but different from unity, then this indicates the pricing discrepancies in international ETFs. In particular, the significant and greater than one $\beta_{1}$ coefficient indicates that international ETFs trade at a discount to their NAVs; the significant but less than one $\beta_{1}$ coefficient suggests that international ETFs trade at a premium to their NAVs.

With regard to pricing inefficiency, the fact that our results of percentage estimates and OLS regression were not different, as reported in Table 6; both measures confirm that Asia-Pacific and European ETFs trade at a premium and that European ETFs are relatively more price efficient. We specifically found that the $\beta_{1}$ coefficient for Asia-Pacific and European ETFs is not equal to one and trades at a premium of 2.10 bps and 0.99 bps to its Asia-Pacific and European NAV, respectively. However, the percentage estimates of Asia-Pacific and European ETFs premium were higher but consistent with OLS results. Overall, we found that international ETFs are not efficiently priced and trade at a premium. Also, European ETFs are relatively more price efficient compared to the Asia-Pacific ETFs because of their lower premium whether they are estimated by percentage or OLS regression approaches. 
Table 6. Pricing inefficiency of international ETFs.

\begin{tabular}{lcc}
\hline & Asia-Pacific ETFs & European ETFs \\
\hline Premium $($ in $\%)$ & 0.0905 & 0.0312 \\
\hline \multicolumn{1}{c}{ OLS Regression: } & & \\
\hline$\alpha$ & $0.0451^{* * *}$ & $0.0027^{* * *}$ \\
& $(0.0251)$ & $(0.0008)$ \\
\hline$\beta_{1}$ & $0.9790 * * *$ & $0.9901^{* * *}$ \\
& $(0.5514)$ & $(0.4215)$ \\
Number of ETFs & 28 & 28 \\
F-Stat $(p-$ value $)$ & 2120 & 2250 \\
$R^{2}$ & 0.0000 & 0.0000 \\
Premium $=\left|\beta_{1}-1\right|$ & 0.9966 & 0.9985 \\
\end{tabular}

Note: This table reports the percentage premium and the estimates of model (3): $C P_{E T F, t}=\alpha+\beta_{1} C P_{N A V, t}+\varepsilon_{t}$ for Asia-Pacific and European ETFs. Prior to running the OLS regression, we tested for the stationarity of trading prices and NAVs series using variance ratio tests. Also, in unreported results, we found that both the trading price and NAV series are stationary by nature. The standard errors for the estimates are heteroscedasticity and autocorrelation consistent standard errors (Newey and West 1987). "****" represents the significance at the $1 \%$ level.

\subsubsection{Does the Pricing Inefficiency Persist over Time in International ETFs?}

Finally, in order to examine that how persistent is the pricing deviation in international ETFs, we regressed the Premium $_{t}$ on its two day lagged values using the second-order autoregressive model $\operatorname{AR}(2)$

$$
\text { Premium }_{t}=\alpha+\beta_{1} \text { Premium }_{t-1}+\beta_{2} \text { Premium }_{t-2}+\varepsilon_{t}
$$

where Premium $_{t}$ represents the magnitude of premium or discount at which international ETFs trade on day $t$.

Table 7 reports the results on persistence of pricing inefficiency in international ETFs. we found that the alpha $(\alpha)$ coefficients are statistically significant for Asia-Pacific and European ETFs, though economically they are below 05 bps and have no material contribution to the premium or discount of international ETFs. This implies that intrinsic frictions in the pricing induce the deviation between the trade prices and NAVs of international ETFs. Also, similarly to the persistence of tracking error, pricing inefficiency in the international ETFs also persisted for two days but it faded away as the tracked time moved from one to two lagged days, as $\beta_{2}<\beta_{1}$. We concluded that there exist significant arbitrage opportunities in international ETFs, which remain available for two days in most of the cases. For the robustness of our results, we re-ran our analyses with a maximum of four lagged values of premium but our results (unreported) remained unchanged and confirmed the significant persistence of pricing inefficiency for two days.

Table 7. Persistence of pricing inefficiency in international ETFs.

\begin{tabular}{lcc}
\hline & Asia-Pacific ETFs & European ETFs \\
\hline \multirow{2}{*}{$\alpha$} & $0.0458^{* * *}$ & $0.0319^{* * *}$ \\
& $(0.0247)$ & $(0.0124)$ \\
\hline \multirow{2}{*}{$\beta_{1}$} & $0.3450^{* * *}$ & $0.1145^{* * *}$ \\
& $(0.1234)$ & $(0.0654)$ \\
\hline \multirow{2}{*}{$\beta_{2}$} & $0.1018^{* * *}$ & $0.0984^{* * *}$ \\
& $(0.0600)$ & $(0.0551)$ \\
Number of ETFs & 28 & 28 \\
$F-$ Stat $(p-$ value) & 2120 & 2250 \\
$R^{2}$ & 0.000 & 0.000 \\
\hline
\end{tabular}

Note: This table reports the estimates of model (4): Premium ${ }_{t}=\alpha+\beta_{1}$ Premium $_{t-1}+\beta_{2}$ Premium $_{t-2}+\varepsilon t$. The standard errors for the estimates are heteroscedasticity and autocorrelation consistent standard errors (Newey and West 1987). “***" represents the significance at the $1 \%$ level. 


\section{Conclusions}

This study evaluates the performance of international ETFs by analyzing their (1) daily, intraday (trading hours) and overnight (non-trading hours) returns and return volatilities, (2) tracking performance and persistence of tracking error and (3) pricing efficiency and persistence of premiums or discounts. Our study sample comprised of 56 US-listed international ETFs, offering exposure to the Asia-Pacific and European markets. Daily historical data was downloaded from Bloomberg for a 10 years' time span from 1 January 2010 to 31 December 2019.

We found that the NAV returns (volatilities) are superior in performance relative to the trading price returns (volatilities) of Asia-Pacific and European ETFs. Next, the comparison of intraday returns (volatilities) and overnight returns (volatilities) revealed that the overnight performance of both Asia-Pacific and European ETFs is relatively better than the intraday performance. Furthermore, our findings indicated that both Asia-Pacific and European ETFs suffer from tracking and pricing errors which persist for two days and fade away the tracked time moves from one to two lagged days. Finally, our results show that European ETFs perform relatively better than the Asia-Pacific ETFs in terms of daily, intraday, overnight, tracking and pricing performance.

The results of this study have several important implications for investors and practitioners. First, the findings provide an understanding of distinguishing behavior of returns and volatilities estimated in trading prices and NAVs of international ETFs. Second, the results related to the intraday and overnight comparison of returns and return volatilities of international ETFs enable investors and practitioners to choose the optimal investment strategy. Third, the larger tracking errors have a material effect on ETF returns and are, therefore, a major concern for investors. They (as large tracking errors) make ETFs ineffective and unattractive by undermining their ability to offer exposure to the benchmark indices. Our findings on the magnitude and persistence of tracking errors, help investors to ensure they have a higher tracking ability prior to investing in international ETFs. Fourth, the pricing inefficiency provides an arbitrage opportunity for large investors. In this respect, our results provide an understanding of the dynamics of pricing inefficiency of international ETFs, which enable investors to implement an idle investment strategy for earning an abnormal return from potential arbitrage opportunities (as and when they occur). Thus, by analyzing the return and return volatility, tracking ability and pricing efficiency of international ETFs, this study equips investors and practitioners with the substantial performance-related information that is useful for making better-informed investment decisions.

Author Contributions: Conceptualization, S.B.; Data curation, S.B.; Formal analysis, S.B.; Methodology, S.B.; Resources, S.B.; Software, S.B.; Supervision, C.G. and C.N.; Visualization, S.B.; Writing-original draft, S.B.; Writing-review \& editing, C.G. All authors have read and agreed to the published version of the manuscript.

Funding: This research received no external funding.

Conflicts of Interest: The authors declare no conflict of interest. 
Appendix A. Profiles of International ETFs Tracking Asia-Pacific and European Indices

Table A1. Profiles of International ETFs Tracking Asia-Pacific Indices.

\begin{tabular}{|c|c|c|c|c|c|c|c|c|c|}
\hline S\# & $\begin{array}{c}\text { ETF } \\
\text { Ticker }\end{array}$ & Name & Benchmark & $\begin{array}{l}\text { Inception } \\
\text { Date }\end{array}$ & $\begin{array}{c}\text { Expense } \\
\text { Ratio }\end{array}$ & Volume & Assets & $\begin{array}{l}\text { Intraday } \\
\text { Volatility }\end{array}$ & $\begin{array}{l}\text { Trading } \\
\text { Frequency }\end{array}$ \\
\hline 1 & AAXJ & iShares MSCI All Country Asia ex Japan ETF & NDUECAXJ Index & $13 / 08 / 2008$ & 0.72 & 621,171 & $4,204,400,916$ & $1.61 \%$ & $93.12 \%$ \\
\hline 2 & AIA & iShares Asia 50 ETF & SPAS50NT Index & $13 / 11 / 2007$ & 0.50 & 32,803 & $468,681,113$ & $1.49 \%$ & $91.19 \%$ \\
\hline 3 & AXJV & iShares Edge MSCI Min Vol Asia ex Japan ETF & M1APJVO Index & 3/06/2014 & 0.35 & 5270 & $6,982,865$ & $0.19 \%$ & $86.11 \%$ \\
\hline 4 & DVYA & iShares Asia/Pacific Dividend ETF & DJAPSDT Index & 23/02/2012 & 0.49 & 11,187 & $41,268,658$ & $0.65 \%$ & $96.98 \%$ \\
\hline 5 & ECNS & iShares MSCI China Small-Cap ETF & MSLUCHNN Index & $28 / 09 / 2010$ & 0.64 & 10,028 & $23,007,626$ & $1.31 \%$ & $89.46 \%$ \\
\hline 6 & EEMA & iShares MSCI Emerging Markets Asia ETF & NDUEEGFA Index & $8 / 02 / 2012$ & 0.49 & 29,020 & $507,817,486$ & $0.86 \%$ & $97.78 \%$ \\
\hline 7 & EIDO & iShares MSCI Indonesia ETF & MIMUINON Index & $5 / 05 / 2010$ & 0.63 & 478,651 & $489,193,848$ & $1.56 \%$ & $95.12 \%$ \\
\hline 8 & ENZL & iShares MSCI New Zealand Capped ETF & M1CXBLRK Index & $1 / 09 / 2010$ & 0.48 & 45,082 & $172,199,717$ & $1.07 \%$ & $90.48 \%$ \\
\hline 9 & EPHE & iShares MSCI Philippines ETF & MIMUPHIN Index & 28/09/2010 & 0.64 & 215,159 & $175,456,225$ & $1.23 \%$ & $89.40 \%$ \\
\hline 10 & EPP & iShares MSCI Pacific ex Japan ETF & NDDUPFXJ Index & 25/10/2001 & 0.49 & 899,051 & $3,092,809,942$ & $1.45 \%$ & $99.92 \%$ \\
\hline 11 & EWA & iShares MSCI Australia ETF & NDDUAS Index & 12/03/1996 & 0.48 & $2,889,905$ & $1,733,576,223$ & $1.59 \%$ & $99.96 \%$ \\
\hline 12 & EWH & iShares MSCI Hong Kong ETF & NDDUHK Index & $12 / 03 / 1996$ & 0.48 & $4,673,897$ & $1,848,097,337$ & $1.42 \%$ & $99.92 \%$ \\
\hline 13 & EWJ & iShares MSCI Japan ETF & NDDUJN Index & 12/03/1996 & 0.48 & $7,268,228$ & $15,998,310,005$ & $1.14 \%$ & $99.92 \%$ \\
\hline 14 & EWM & iShares MSCI Malaysia ETF & NDDUMAF Index & 12/03/1996 & 0.48 & 521,496 & $439,561,297$ & $1.41 \%$ & $99.92 \%$ \\
\hline 15 & EWS & iShares MSCI Singapore Capped ETF & M1CXBLY Index & $12 / 03 / 1996$ & 0.48 & $1,221,571$ & $575,266,118$ & $1.38 \%$ & $99.92 \%$ \\
\hline 16 & EWT & iShares MSCI Taiwan Capped ETF & M1CXBLZ Index & 20/06/2000 & 0.64 & $4,719,238$ & $3,652,582,226$ & $1.45 \%$ & $99.96 \%$ \\
\hline 17 & EWY & iShares MSCI South Korea Capped ETF & M1CXKR5I Index & 9/05/2000 & 0.64 & $2,909,692$ & $3,739,590,053$ & $1.53 \%$ & $99.92 \%$ \\
\hline 18 & FXI & iShares China Large-Cap ETF & TXINOUNU Index & $5 / 10 / 2004$ & 0.74 & $21,230,847$ & $3,434,027,411$ & $1.83 \%$ & $99.96 \%$ \\
\hline 19 & HEWJ & iShares Currency Hedged MSCI Japan ETF & MOJPHUSD Index & $31 / 01 / 2014$ & 1.02 & 559,512 & $1,248,128,836$ & $0.89 \%$ & $97.35 \%$ \\
\hline 20 & INDA & iShares MSCI India ETF & NDEUSIA Index & 2/02/2012 & 0.71 & 991,824 & $4,969,106,604$ & $1.03 \%$ & $98.17 \%$ \\
\hline 21 & INDY & iShares India 50 ETF & BXTRNIF\$ Index & 18/11/2009 & 0.93 & 165,657 & $1,114,897,457$ & $1.12 \%$ & $88.89 \%$ \\
\hline 22 & IPAC & iShares Core MSCI Pacific ETF & M1PCIME Index & 10/06/2014 & 0.10 & 71,536 & $1,131,429,121$ & $0.76 \%$ & $85.58 \%$ \\
\hline 23 & JPMV & iShares Edge MSCI Min Vol Japan ETF & M1JPMVOE Index & 3/06/2014 & 0.30 & 7248 & $32,071,990$ & $0.36 \%$ & $86.11 \%$ \\
\hline 24 & JPXN & iShares JPX-Nikkei 400 ETF & JPNKNTR Index & 23/10/2001 & 0.48 & 23,246 & $90,492,360$ & $1.00 \%$ & $99.92 \%$ \\
\hline 25 & $\mathrm{MCHI}$ & iShares MSCI China ETF & NDEUCHF Index & 29/03/2011 & 0.64 & 585,249 & $2,531,987,300$ & $1.09 \%$ & $95.90 \%$ \\
\hline 26 & SCJ & iShares MSCI Japan Small-Cap ETF & NCUAJN Index & 20/12/2007 & 0.48 & 19,299 & $199,583,535$ & $0.97 \%$ & $90.20 \%$ \\
\hline 27 & SMIN & iShares MSCI India Small-Cap ETF & MSLUINDN Index & 8/02/2012 & 0.80 & 14,031 & $210,863,316$ & $1.37 \%$ & $97.78 \%$ \\
\hline 28 & THD & iShares MSCI Thailand Capped ETF & M1CXTH5I Index & $26 / 03 / 2008$ & 0.63 & 208,539 & $381,076,869$ & $1.54 \%$ & $97.44 \%$ \\
\hline
\end{tabular}


Table A2. Profiles of International ETFs tracking European Indices.

\begin{tabular}{|c|c|c|c|c|c|c|c|c|c|}
\hline S\# & $\begin{array}{c}\text { ETF } \\
\text { Ticker }\end{array}$ & Name & Benchmark & $\begin{array}{c}\text { Inception } \\
\text { Date }\end{array}$ & $\begin{array}{c}\text { Expense } \\
\text { Ratio }\end{array}$ & Volume & Assets & $\begin{array}{c}\text { Intraday } \\
\text { Volatility }\end{array}$ & $\begin{array}{c}\text { Trading } \\
\text { Frequency }\end{array}$ \\
\hline 29 & EDEN & iShares MSCI Denmark Capped ETF & M1DK5IM Index & $25 / 01 / 2012$ & 0.53 & 21,667 & $67,454,790$ & $0.78 \%$ & $98.73 \%$ \\
\hline 30 & EFNL & iShares MSCI Finland Capped ETF & M1FI5IM Index & $25 / 01 / 2012$ & 0.53 & 12,290 & $46,299,454$ & $0.76 \%$ & $98.65 \%$ \\
\hline 31 & EIRL & iShares MSCI Ireland Capped ETF & M1CXIEAC Index & $5 / 05 / 2010$ & 0.48 & 29,498 & $71,790,441$ & $1.24 \%$ & $95.24 \%$ \\
\hline 32 & EIS & iShares MSCI Israel Capped ETF & MISCNU Index & $26 / 03 / 2008$ & 0.64 & 48,263 & $92,458,364$ & $1.38 \%$ & $97.40 \%$ \\
\hline 33 & ENOR & iShares MSCI Norway Capped ETF & M1NO5IM Index & $23 / 01 / 2012$ & 0.53 & 16,388 & $33,714,329$ & $0.93 \%$ & $98.81 \%$ \\
\hline 34 & EPOL & iShares MSCI Poland Capped ETF & M1CXPL5I Index & $25 / 05 / 2010$ & 0.64 & 186,410 & $356,139,805$ & $1.45 \%$ & $94.39 \%$ \\
\hline 35 & ERUS & iShares MSCI Russia Capped ETF & MSEURU\$N Index & $9 / 11 / 2010$ & 0.64 & 169,008 & $612,767,266$ & $1.70 \%$ & $87.81 \%$ \\
\hline 36 & EUFN & iShares MSCI Europe Financials ETF & NDRUFNCL Index & $20 / 01 / 2010$ & 0.48 & 175,247 & $1,905,790,798$ & $1.33 \%$ & $99.26 \%$ \\
\hline 37 & EUMV & iShares Edge MSCI Min Vol Europe ETF & MO0IER\$O Index & $3 / 06 / 2014$ & 0.25 & 16,448 & $35,392,866$ & $0.51 \%$ & $86.11 \%$ \\
\hline 38 & EWD & iShares MSCI Sweden Capped ETF & M1CXBLV Index & $12 / 03 / 1996$ & 0.48 & 257,130 & $479,030,207$ & $1.68 \%$ & $99.92 \%$ \\
\hline 39 & EWG & iShares MSCI Germany ETF & NDDUGR Index & $12 / 03 / 1996$ & 0.48 & $3,339,165$ & $4,705,640,819$ & $1.54 \%$ & $99.92 \%$ \\
\hline 40 & EWGS & iShares MSCI Germany Small-Cap ETF & NCUDGR Index & $25 / 01 / 2012$ & 0.59 & 7727 & $51,310,779$ & $0.72 \%$ & $98.73 \%$ \\
\hline 41 & EWI & iShares MSCI Italy Capped ETF & M1CXBLRM Index & $12 / 03 / 1996$ & 0.48 & 569,897 & $887,541,157$ & $1.69 \%$ & $99.92 \%$ \\
\hline 42 & EWK & iShares MSCI Belgium Capped ETF & M1CXBLRJ Index & $12 / 03 / 1996$ & 0.48 & 173,845 & $67,755,695$ & $1.37 \%$ & $99.92 \%$ \\
\hline 43 & EWL & iShares MSCI Switzerland Capped ETF & M1CXBLRO Index & $12 / 03 / 1996$ & 0.48 & 399,918 & $1,243,064,689$ & $1.23 \%$ & $99.96 \%$ \\
\hline 44 & EWN & iShares MSCI Netherlands ETF & M1CXNIC Index & $12 / 03 / 1996$ & 0.48 & 160,552 & $202,399,765$ & $1.36 \%$ & $99.96 \%$ \\
\hline 45 & EWO & iShares MSCI Austria Capped ETF & M1CXBLRQ Index & $12 / 03 / 1996$ & 0.48 & 151,219 & $240,539,136$ & $1.55 \%$ & $99.96 \%$ \\
\hline 46 & EWP & iShares MSCI Spain Capped ETF & M1CXBLRP Index & $12 / 03 / 1996$ & 0.48 & 662,447 & $1,534,713,122$ & $1.66 \%$ & $99.92 \%$ \\
\hline 47 & EWQ & iShares MSCI France ETF & NDDUFR Index & 12/03/1996 & 0.48 & 529,990 & $636,626,394$ & $1.51 \%$ & $99.96 \%$ \\
\hline 48 & EWU & iShares MSCI United Kingdom ETF & NDDUUK Index & $12 / 03 / 1996$ & 0.48 & $1,009,349$ & $2,656,216,756$ & $1.43 \%$ & $99.92 \%$ \\
\hline 49 & EWUS & iShares MSCI United Kingdom Small-Cap ETF & NCUDUK Index & $25 / 01 / 2012$ & 0.59 & 7553 & $35,632,245$ & $0.69 \%$ & $98.65 \%$ \\
\hline 50 & EZU & iShares MSCI Eurozone ETF & NDDUEMU Index & $25 / 07 / 2000$ & 0.48 & $2,529,517$ & $13,931,762,827$ & $1.49 \%$ & $99.96 \%$ \\
\hline 51 & HEWG & iShares Currency Hedged MSCI Germany ETF & MODEHUSD Index & $31 / 01 / 2014$ & 1.01 & 699,196 & $685,330,286$ & $1.00 \%$ & $97.35 \%$ \\
\hline 52 & HEZU & iShares Currency Hedged MSCI Eurozone ETF & MOEMHUSR Index & 9/07/2014 & 1.10 & 941,674 & $1,881,111,305$ & $0.99 \%$ & $82.94 \%$ \\
\hline 53 & IEUR & iShares Core MSCI Europe ETF & MIMUEURN Index & $10 / 06 / 2014$ & 0.10 & 120,351 & $3,208,069,017$ & $0.96 \%$ & $85.58 \%$ \\
\hline 54 & IEUS & iShares MSCI Europe Small-Cap ETF & M1EUSC Index & $12 / 11 / 2007$ & 0.40 & 7369 & $173,865,041$ & $1.29 \%$ & $91.31 \%$ \\
\hline 55 & IEV & iShares Europe ETF & SPE35CUN Index & $25 / 07 / 2000$ & 0.60 & 630,513 & $3,213,215,541$ & $1.37 \%$ & $99.92 \%$ \\
\hline 56 & TUR & iShares MSCI Turkey ETF & MIMUTURN Index & $26 / 03 / 2008$ & 0.64 & 289,726 & $375,926,396$ & $2.14 \%$ & $97.44 \%$ \\
\hline
\end{tabular}

important inform A reports the profile of international ETFs offering exposure to Asia-Pacific (in Table A1) and European (in Table A2) markets. Each panel has 28 ETFs and provides trading frequency of each ETFs. 


\section{Appendix B. Measurement of Variables}

Table A3. Variables Measured in Trading price and NAV.

\begin{tabular}{ccc}
\hline Variables & In Terms of Trading Price & In Terms of NAV \\
\hline Daily return & $R_{E T F, t}=\log \left(C P_{E T F, t}\right)-\log \left(C P_{E T F, t-1}\right)$ & $R_{N A V, t}=\log \left(C P_{N A V, t}\right)-\log \left(C P_{N A V, t-1}\right)$ \\
\hline Daily return volatility & $\sigma_{E T F}=\sqrt{\frac{\sum_{t=1}^{n}\left(R_{E T F, t}-\overline{R_{E T F}}\right)^{2}}{n-1}}$ & $\sigma_{N A V}=\sqrt{\frac{\sum_{t=1}^{n}\left(R_{N A V, t}-\overline{R_{N A V}}\right)^{2}}{n-1}}$ \\
\hline Tracking error (First Measure) & $T E 1_{E T F, t}=\frac{\sum_{t=1}^{n}\left|R_{E T F}-R_{\text {Ind }}\right|}{n}$ & $T E 1_{N A V, t}=\frac{\sum_{t=1}^{n}\left|R_{N A V}-R_{\text {Ind }}\right|}{n}$ \\
\hline Tracking error (Second Measure) & $T E 2_{E T F, t}=\sqrt{\frac{\sum_{t=1}^{n}\left[\left(R_{E T F}-R_{\text {Ind }}\right)-\overline{\left(R_{E T F}-R_{\text {Ind }}\right)}\right]^{2}}{n-1}}$ & $\sqrt{\frac{\sum_{t=1}^{n}\left[\left(R_{N A V}-R_{\text {Ind }}\right)-\overline{\left.\left(R_{N A V}-R_{\text {Ind }}\right)\right]^{2}}\right.}{n-1}}$ \\
\hline
\end{tabular}

Table A4. Variables Measured for Intraday and Overnight Periods.

\begin{tabular}{lcc}
\hline \multicolumn{1}{c}{ Variables } & Intraday & Overnight \\
\hline Return & $R_{\text {day }}=\log \left(C P_{E T F, t}\right)-\log \left(O P_{E T F, t}\right)$ & $R_{\text {night }}=\log \left(O P_{E T F, t}\right)-\log \left(C P_{E T F, t-1}\right)$ \\
\hline \multirow{2}{*}{ Return volatility } & $\sigma_{\text {day }}=\sqrt{\frac{\sum_{t=1}^{n}\left(R_{\text {day }, t}-\overline{R_{\text {day }}}\right)^{2}}{n-1}}$ & $\sigma_{\text {night }}=\sqrt{\frac{\sum_{t=1}^{n}\left(R_{\text {night }, t}-\overline{R_{\text {night }}}\right)^{2}}{n-1}}$ \\
\hline
\end{tabular}

Note: Appendix B reports the measurement of variables in Tables A3 and A4. Table A3 is for variables measured in trading price and NAV while Table A4 is for variables measured for intraday and overnight periods.

\section{References}

Ackert, Lucy, and Yisong Tian. 2008. Arbitrage, liquidity, and the valuation of exchange traded funds. Financial Markets, Institutions $\mathcal{E}$ Instruments 17: 331-62.

Blitz, David, and Joop Huij. 2012. Evaluating the performance of global emerging markets equity exchange-traded funds. Emerging Markets Review 13: 149-58. [CrossRef]

Campbell, John Y., Andrew W. Lo, and Archie C. MacKinlay. 1997. The Econometrics of Financial Markets. Princeton: Princeton University Press.

Chan, Kalok, Mark Chockalingam, and Kent Lai. 2000. Overnight information and intraday trading behavior: Evidence from NYSE cross-listed stocks and their local market information. Journal of Multinational Financial Management 10: 495-509. [CrossRef]

Chang, Eric, Cheol S. Eun, and Richard Kolodny. 1995. International diversification through closed-end country funds. Journal of Banking \& Finance 19: 1237-63.

Chen, Jo-Hui, and Edwards Nicholas. 2020. The Study of Spillover, Risk, and Leverage Effects: Smart Beta ETF Management Style. Paper presented at EconWorld2020@Porto, Porto, Portugal, January 23-25.

Chow, Victor, and Karen Denning. 1993. A simple multiple variance ratio test. Journal of Econometrics 58: $385-401$. [CrossRef]

Delcoure, Natalya, and Maosen Zhong. 2007. On the premiums of iShares. Journal of Empirical Finance 14: 168-95. [CrossRef]

Dickson, Joel, Lauren Mance, and James Rowley Jr. 2013. Understanding Synthetic ETFs. Available online: https://www.vanguard.com.hk/documents/understand-synthetic-etfs-tlrv.pdf (accessed on 27 June 2020).

Engle, Robert, and Debojyoti Sarkar. 2006. Premiums-discounts and exchange traded funds. Journal of Derivatives 13: 27. [CrossRef]

Ferri, Richard A. 2011. The ETF Book: All You Need to Know about Exchange-Traded Funds. Hoboken: John Wiley \& Sons.

Frino, Alex, and David Gallagher. 2001. Tracking S\&P 500 index funds. The Journal of Portfolio Management 28: $44-55$.

Gutierrez, Jose A., Valeria Martinez, and Yiuman Tse. 2009. Where does return and volatility come from? The case of Asian ETFs. International Review of Economics \& Finance 18: 671-79. [CrossRef]

Hughen, John, and Prem Mathew. 2009. The efficiency of international information flow: Evidence from the ETF and CEF prices. International Review of Financial Analysis 18: 40-49. [CrossRef]

Kang, Long, and Simon Babbs. 2012. Modeling overnight and daytime returns using a multivariate generalized autoregressive conditional heteroskedasticity copula model. The Journal of Risk 14: 35. [CrossRef] 
Levy, Ariel, and Offer Lieberman. 2013. Overreaction of country ETFs to US market returns: Intraday vs. daily horizons and the role of synchronized trading. Journal of Banking $\mathcal{E}$ Finance 37: 1412-21. [CrossRef]

Lo, Andrew, and Andrew MacKinlay. 1988. Stock market prices do not follow random walks: Evidence from a simple specification test. The Review of Financial Studies 1: 41-66. [CrossRef]

Ma, Zhe J. 2015. Three Essays on Exchange Traded Funds and Emerging Markets. Hamilton: McMaster University.

Maurer, Frantz, and Seth Williams. 2015. Physically Versus Synthetically Replicated Trackers: Is There A Difference in Terms of Risk? Journal of Applied Business Research 31: 131. [CrossRef]

Mistry, Manooj. 2013. ETFs Bridging the Gap to Emerging Markets. The Journal of Index Investing 4: 118-21. [CrossRef]

Newey, Whitney, and Kenneth West. 1987. A Simple, Positive Semi-Definite, Heteroskedasticity and Autocorrelation Consistent Covariance Matrix. Econometrica 55: 703-8. [CrossRef]

Pontiff, Jeffrey. 1997. Excess volatility and closed-end funds. The American Economic Review 87: 155-69.

Pope, Peter F., and Pradeep K. Yadav. 1994. Discovering errors in tracking error. The Journal of Portfolio Management 20: 27-32. [CrossRef]

Purohit, Harsh, Nidhi Choudhary, and Parul Tyagi. 2014. An Evaluation of Tracking Error on World Indices ETFs Traded in India [dagger]. IUP Journal of Applied Finance 20: 41-52.

PwC. 2016. ETFs: A Roadmap to Growth. Available online: https://www.pwc.com/gx/en/asset-management/ publications/pdfs/etfs-a-roadmap-to-growth.pdf (accessed on 20 July 2020).

Ramos, João Pedro Martelo. 2015. Tracking Ability of Global Emerging Markets Exchange Traded Funds. Master's dissertation, ISCTE Business School, Lisboa, Portugal.

Roll, Richard. 1992. A mean/variance analysis of tracking error. The Journal of Portfolio Management 18: 13-22. [CrossRef]

Rompotis, Gerasimos. 2015. On the Trading Behavior of Emerging Market ETFs. The Journal of Trading 10: 56-86. [CrossRef]

Shin, Sangheon, and Gökçe Soydemir. 2010. Exchange-traded funds, persistence in tracking errors and information dissemination. Journal of Multinational Financial Management 20: 214-34. [CrossRef]

Shum, Nolan Pauline. 2010. How Passive are International ETFs? A Study of Their Intraday Behaviour. Available online: https://ssrn.com/abstract=1653159 (accessed on 28 June 2020). [CrossRef]

Svetina, Marko. 2010. Exchange traded funds: Performance and competition. Journal of Applied Finance (Formerly Financial Practice and Education) 20. [CrossRef]

Tse, Yiuman, and Valeria Martinez. 2007. Price discovery and informational efficiency of international iShares funds. Global Finance Journal 18: 1-15. [CrossRef] 